\title{
PENENTUAN NILAI KONTRAK OPSI TIPE BINARY PADA KOMODITAS KAKAO MENGGUNAKAN METODE QUASI MONTE CARLO DENGAN BARISAN BILANGAN ACAK FAURE
}

\author{
Dewa Ayu Agung Putri Ratnasari ${ }^{1 \S}$, Komang Dharmawan ${ }^{2}$, Desak Putu Eka Nilakusmawati ${ }^{3}$ \\ ${ }^{1}$ Jurusan Matematika, Fakultas MIPA - Universitas Udayana [Email: gung_putri95@yahoo.com] \\ ${ }^{2}$ Jurusan Matematika, Fakultas MIPA - Universitas Udayana [Email: dharmawan.komang@gmail.com] \\ ${ }^{3}$ Jurusan Matematika, Fakultas MIPA - Universitas Udayana [Email: nilakusmawati@unud.ac.id] \\ ${ }^{\S}$ Corresponding Author
}

\begin{abstract}
Contract options are the most important part of an investment strategy. An option is a contract that entitles the owner or holder to sell an asset on a designated maturity date. A binary or asset-ornothing option is an option in which the option holder will perform or not the option. There are many methods used in determining the option contract value, one of this is the Monte Carlo Quasi method of the Faure random. The purpose of this study is to determine the value of binary type option contract using the Quasi Monte Carlo method of the Faure random and compare with the Monte Carlo method. The results of this study indicate that the option contract calculated by the Monte Carlo Quasi method results in a more fair value. Monte Carlo method simulation 10.000 generate standard error is 0.9316 and the option convergence at 18.9144. While Quasi Monte Carlo simulation 3000 generate standard error is 0.09091 and the option convergence at 18.8203. This show the Quasi Monte Carlo method reaches a faster convergent of Monte Carlo method.
\end{abstract}

Keywords: Option, Binary Option, Quasi Monte Carlo, Faure Random Number, Monte Carlo

\section{PENDAHULUAN}

Penentuan nilai kontrak opsi merupakan bagian terpenting dalam menentukan strategi berinvestasi. Kontrak opsi dapat digunakan untuk meminimalkan risiko sekaligus memaksimalkan keuntungan dengan daya ungkit atau leverage yang besar (Bodie et al., 2006). Kontrak opsi merupakan instrumen derivatif yang diperjualbelikan dipasar derivatif. Instrumen derivatif adalah produk finansial yang sebagian atau keseluruhannya merupakan turunan dari suatu aktiva. Instrument derivatif banyak digunakan pada aktiva keuangan seperti saham maupun komoditas (Siahaan, 2008).

Komoditas adalah suatu benda nyata yang relatif mudah untuk diperdagangkan, dapat disimpan untuk jangka waktu tertentu dan dapat dipertukarkan dengan produk lainnya dengan jenis yang sama. Komoditas yang umumnya ditransaksikan pada sektor pertanian dan perkebunan salah satunya yaitu kakao. Kakao merupakan salah satu komoditas andalan perkebunan yang perananya cukup tinggi bagi perekonomian nasional dan devisa Negara (Badan Perijinan \& Penanaman Modal Daerah Provinsi Kalimantan Timur, 2009). Kakao juga berperan dalam mendorong pengembangan wilayah dan pengembangan agroindustri. Menurut Elfiana (2014) volume ekspor-impor kakao dari tahun ke tahun selalu mengalami perubahan, dikarenakan adanya faktor-faktor yang memengaruhi ekspor-impor. Salah satu penyebabnya dalah faktor harga yang berfluktuatif dari tahun ke tahun, fluktuasi harga dipengaruhi oleh permintaan, penawaran, produksi, stok, kondisi iklim dan cuaca.

Strategi yang dilakukan untuk melindungi diri dari perubahan nilai investasi komoditas dengan melakukan kontrak opsi tipe binary atau asset-or-nothing. Asset-or-nothing merupakan penentuan apakah pemegang opsi akan 
melaksanakan atau tidak opsinya. Kontrak opsi digunakan untuk menentukan nilai yang adil (fair) antara pembeli opsi dan penjual opsi sehingga tidak ada pihak yang diuntungkan dan dirugikan. Metode yang digunakan dalam menentukan nilai kontrak opsi yaitu metode Monte Carlo dan metode Quasi Monte Carlo.

Menurut Boyle (1977) metode Monte Carlo merupakan perhitungan numerik yang mengandung integral multidimensi yang digunakan dalam komputasi keuangan. Kelemahan dari metode Monte Carlo adalah nilai yang dihasilkan cenderung tidak konvergen dan sulit diaplikasikan pada nilai opsi yang multivariabel.

Metode Quasi Monte Carlo mampu memberikan pendekatan yang akurat dibandingkan dengan metode Monte Carlo (Paskov, 1995). Metode Quasi Monte Carlo merupakan metode Monte Carlo yang menggunakan barisan bilangan acak. Barisan bilangan acak antara lain Van der corput, Halton, Faure, dan Sobol. Pada penelitian ini akan menggunakan barisan bilangan acak Faure. Penelitian metode Quasi Monte Carlo pernah digunakan oleh Uyanto (2007) yang membahas mengenai perbandingan Quasi Monte Carlo barisan kuasi-acak Halton dan barisan kuasiacak Sobol dalam option pricing. Penelitian selanjutnya oleh Mahayoga, et al. (2014) juga menggunakan metode Quasi Monte Carlo barisan kuasi-acak Halton untuk mengetahui tingkat keakuratan simulasi menggunakan Mean Absolute Percentage Error (MAPE).

Berdasarkan uraian tersebut, penelitian ini bertujuan untuk menentukan nilai kontrak opsi tipe binary menggunakan metode Quasi Monte Carlo barisan bilangan acak Faure. Selanjutnya nilai simulasi yang diperoleh menggunakan metode Quasi Monte Carlo akan dibandingkan dengan nilai simulasi yang diperoleh dari metode Monte Carlo akan dilihat kekonvergenan yang dihasilkan dari simulasi tersebut.

Kontrak Opsi binary atau asset-or-nothing pada dasarnya merupakan cara untuk memprediksi ke arah mana nilai komoditas akan bergerak pada waktu jatuh tempo yang telah ditetapkan. Pemilik kontrak tidak mendapatkan hasil atau bernilai nol apabila nilai komoditasnya lebih besar dari harga kesepakatannya, sebaliknya pemilik kontrak mendapatkan hasil apabila nilai komoditasnya lebih kecil dari harga kesepakatan.

Simbol $\mathrm{P}$ merupakan penentuan untuk menghitung pay-off asset-or-nothing dapat dirumuskan (Hull, 2009):

$$
\mathrm{P}= \begin{cases}\gamma, & S_{t}<k \\ 0, & S_{t} \geq k\end{cases}
$$

dengan simbol $\gamma$ merupakan nilai opsi put assetor-nothing dapat ditulis sebagai berikut:

$$
\gamma=e^{-r T}\left(K-S_{t}\right)
$$

Monte Carlo yaitu suatu simulasi untuk menentukan angka random dari data sampel. Metode Monte Carlo menggunakan bilangan acak berdistribusi normal baku yaitu:

$$
S(T)=S(0) e^{\left[\left(r-\frac{\sigma^{2}}{2}\right) \Delta t+\sigma \epsilon \sqrt{\Delta t}\right]}
$$

dengan $S(T)$ merupakan nilai komoditas pada saat mendatang, $S(0)$ yaitu harga saham awal, $r$ adalah tingkat suku bunga, $\sigma$ merupakan volatilitas dan $\epsilon$ bilangan acak berdistribusi normal $(\epsilon \sim N(0,1))$.

Barisan bilagan Faure menggunakan berdimensi- $s$ yaitu basis $b$ bilangan prima terkecil $b \geq s$ dan $b \geq 2$ (Joy et al., 1996). Dimensi dalam ruang sistematis didefinisikan sebagai banyaknya koordinat minimum yang diperlukan untuk menentukan suatu titik di dalamnya. Langkah-langkah untuk membangkitkan bilangan acak Faure (Kroese et al., 2011):

1. Tentukan $r=\lfloor\ln N / \ln b\rfloor+1$, dengan $N$ adalah banyak iterasi yang digunakan. Nilai $r$ digunakan untuk menentukan digit yang akan digunakan.

2. Tentukan $\mathbf{b}=b^{-1}, b^{-2}, \ldots, b^{-r}$, dengan $b$ merupakan nilai basis.

3. Untuk $n=0$ sampai $N$, ubah $n$ menjadi bentuk basis, dalam bentuk vektor $\mathrm{a}=$ $\left[a_{1}, a_{2}, \ldots, a_{r}\right]^{T}$.

4. Untuk $k=1, \ldots, s$, hitung $\mathbf{a}_{k}=G^{k-1}$. a , $G^{k-1}$ merupakan matriks triangular atas.

5. Untuk $k=1, \ldots, s$, hitung $X_{n k}=\mathbf{b} \cdot \mathbf{a}_{k}$, $X_{n k}$ merupakan barisan bilangan acak Faure 


$$
\begin{array}{lll}
\text { yang dapat ditulis } & X_{n k}= \\
{\left[X_{n 1}, X_{n 2}, \ldots, X_{n s}\right]^{T} .} &
\end{array}
$$

6. Langkah selesai sampai $n=N$, jika tidak ulangi pada langkah 3 .

\section{METODE PENELITIAN}

Jenis penelitian ini merupakan studi kasus terhadap nilai kontrak opsi tipe binary yang datanya berasal dari data historis komoditas kakao. Studi kasus dilakukan dengan melakukan simulasi untuk penentuan nilai komoditas pada waktu $T$ yaitu selama enam bulan (31 Maret 2017 sanpai 30 September 2017). Data yang digunakan yaitu data sekunder berupa data harian harga komoditas kakao. Data diambil dari situs www.investing.com.

Langkah-langkah yang digunakan untuk menentukan nilai kontrak opsi meggunakan metode Quasi Monte Carlo barisan bilangan acak Faure adalah:

1. Mencari dan menentukan data historis komoditas kakao.

2. Menghitung tingkat pengembalian (return) dari nilai komoditas kakao dengan persamaan:

$$
R_{t}=\ln \left(\frac{S_{t+1}}{S_{t}}\right)
$$

3. Menetapkan parameter yang diperlukan untuk mensimulasi nilai komoditas yaitu $S_{0}$ (nilai komoditas awal), $T$ (waktu jatuh tempo), $K$ (harga kesepakatan), $r$ (tingkat suku bunga), dan $\sigma$ (standar deviasi) yang diperoleh dari data historis. Nilai $T$ dan $K$ sudah ditetapkan sebelumnya.

4. Melakukan simulasi nilai komoditas menggunakan persamaan (2). Substitusikan parameter $S_{0}$ (nilai komoditas awal), $T$ (waktu jatuh tempo), $K$ (harga kesepakatan), $r$ (tingkat suku bunga), dan $\sigma$ (standar deviasi) pada persamaan (2). Bilangan acak yang dibangkitkan disesuaikan dengan metode yang digunakan. Saat melakukan simulasi menggunakan metode Monte Carlo variabel $\epsilon$ merupakan bilangan acak berdistribusi normal. Sedangkan saat melakukan simulasi menggunakan metode
Quasi Monte Carlo variabel $\epsilon$ merupakan barisan bilangan acak Faure.

5. Menentukan nilai pay-off opsi put menggunakan asset-or-nothing pada persamaan (1).

6. Menaksir nilai opsi put dengan merataratakan nilai pay-off dari opsi put.

7. Membandingkan nilai opsi put yang diperoleh dari metode Quasi Monte Carlo dan metode Monte Carlo. Akan dilihat nilai kekonvergenan dari hasil simulasi.

\section{HASIL DAN PEMBAHASAN}

\section{Karakteristik Data}

Data yang digunakan pada penelitian ini adalah data nilai harian komoditas kakao periode 02 Januari 2012 sampai 31 Maret 2017. Karakteristik data ditentukan menggunakan nilai tingkat pengembalian (return) menggunakan persamaan (3). Perhitungan yang dilakukan adalah menghitung nilai saat $t=1$ sebagai berikut:

$$
\begin{aligned}
R_{1} & =\ln \left(\frac{2115}{2108.5}\right) \\
& =0.003078
\end{aligned}
$$

Karakteristik data dapat dilihat dengan menghitung nilai statistika deskriptif dari tingkat pengembalian (return). Nilai statistika deskriptif diperoleh dengan menghitung nilai mean, variance, skewness, dan kurtosis menggunakan software Matlab sehingga diperoleh hasil pada Tabel 1.

Tabel 1. Nilai Statistika Deskriptif

\begin{tabular}{|l|l|}
\hline Karakteristik & Nilai \\
\hline Mean & -0.0000048404 \\
\hline Variance & 0.000227 \\
\hline Skweness & 0.168656 \\
\hline Kurtosis & 4.3765 \\
\hline
\end{tabular}

Pada Tabel 1 menunjukkan bahwa tidak terdapat tingkat keuntungan pada komoditas kakao, hal ini ditunjukkan nilai return pada data bernilai negatif. Model data return nilai komoditas kakao memiliki bentuk yang tidak simetris. Hal ini ditunjukkan dengan nilai karakteristik data memiliki nilai skewnes yang positif yang mengakibatkan data menceng ke kanan. 
Kemudian nilai kurtosis yang tidak normal yaitu 4.3765 nilai kurtosis normalnya adalah 3, yang disebabkan oleh banyaknya data ekstrem pada data.

\section{Variabel-variabel Penentuan Nilai Opsi}

Dalam penentuan nilai kontrak opsi tipe binary terdapat variabel-variabel yang digunakan diantaranya:

1. Menentukan Harga Saham Awal $\left(S_{0}\right)$

Harga saham awal dapat dilihat pada data historis komoditas kakao tanggal 31 Maret 2017 yaitu sebesar US\$2,095.

2. Menetukan Watu Jatuh Tempo (T)

Waktu jatuh tempo diperoleh dari lamanya kontrak opsi selama enam bulan atau 0,5 tahun.

3. Menentukan Nilai Volatilitas $(\sigma)$

Nilai volatilitas pada penelitian ini dihitung menggunakan nilai return data harian komoditas kakao ditunjukkan sebagai berikut:

$\sigma=\sqrt{\text { Variance }}=\sqrt{0.000227}=0.01501$

Perhitungan tersebut masih merupakan nilai volatilitas dalam harian. Mengingat bahwa nilai volatilitas yang diperlukan dalam tahunan yaitu:

$$
\begin{aligned}
\sigma= & \sqrt{\sigma^{2} \times \mathrm{k}} \\
= & \sqrt{0.000227 \times 252} \\
= & 0.238276363
\end{aligned}
$$

sehingga diperoleh nilai volatilitas dalam tahunan sebesar 0.238276363 .

4. Menentukan Tingkat Suku Bunga Bebas Risiko ( $r$ )

Tingkat suku bunga yang digunakan yaitu tingkat suku bunga yang dikeluarkan oleh bank Indonesia yaitu sebesar 6,50\%.

5. Menentukan Harga Kesepakatan $(K)$

Harga kesepakatan yaitu harga yang diperoleh dari kesepakatan antara pihak pembeli dan penjual opsi. Pada penelitian ini ditentukan harga kesepakatan antara penjual dan pembeli sebesar 2,100 US\$.

\section{Proses dan Implementasi Hasil}

Proses yang dilakukan untuk memperoleh nilai kontrak opsi tipe binary dilakukan dengan beberapa tahapan yaitu tahapan pertama menghitung nilai kontrak opsi put tipe binary menggunakan metode Monte Carlo. Metode Monte Carlo menggunakan pembangkitan bilangan acak berdistribusi normal.

Tahapan kedua yaitu menghitung nilai kontrak opsi put tipe binary menggunakan metode Quasi Monte Carlo. Metode Quasi Monte Carlo merupakan metode Monte Carlo yang menggunakan barisan bilangan acak dalam melakukan simulasi. Pada penelitian ini digunakan barisan bilangan acak Faure.

Tahapan akhir yaitu membandingkan nilai opsi put yang diperoleh dari metode Monte Carlo dan Quasi Monte Carlo. Selanjutnya dilihat nilai kekonvergenan yang dihasilkan dari simulasi.

\section{Simulasi Nilai Kontrak Opsi Tipe Binary menggunakan Metode Monte Carlo dan Quasi Monte Carlo}

Simulasi nilai komoditas dengan metode Monte Carlo mengikutsertakan pembangkit bilangan acak berdistribusi normal, menggunakan persamaan (2). Metode Quasi Monte Carlo adalah metode Monte Carlo yang menggunakan barisan bilangan acak untuk mensimulasi harga komoditas. Persamaan yang digunakan dalam mensimulasi nilai komoditas kakao sama dengan persamaan pada Monte Carlo yang membedakan hanya pada $\epsilon$. Pada Monte Carlo menggunakan barisan bilangan acak berdistribusi normal, sedangkan pada Quasi Monte Carlo mengguakan barisan bilangan acak Faure. Setelah mensimulasi harga komoditas kemudian menghitung nilai pay-off. Seanjutnya adalah menaksir nilai opsi dengan merata-ratakan nilai pay-off dari opsi tersebut.

Simulasi yang dilakukan dibantu menggunakan software Matlab. Hasil dari simulasi dapat dilihat pada Tabel 2. 
Tabel 2. Perbandingan Nilai Kontrak Opsi Tipe Binary menggunakan Metode Monte Carlo dan Quasi Monte Carlo

\begin{tabular}{|c|c|c|c|c|c|c|}
\hline \multirow{2}{*}{$\mathrm{N}$} & \multicolumn{3}{|c|}{ Monte Carlo } & \multicolumn{3}{c|}{$\begin{array}{c}\text { Quasi Monte Carlo } \\
\text { Barisan Faure }\end{array}$} \\
\cline { 2 - 7 } & $\begin{array}{c}\text { Nilai Opsi } \\
\text { Put }\end{array}$ & $\begin{array}{c}\text { Standard } \\
\text { Error }\end{array}$ & $\begin{array}{c}\text { Waktu } \\
\text { (Detik) }\end{array}$ & $\begin{array}{c}\text { Nilai Opsi } \\
\text { Put }\end{array}$ & $\begin{array}{c}\text { Standard } \\
\text { Error }\end{array}$ & Waktu (Detik) \\
\hline 100 & 42.8035 & 15.7986 & 0.17490 & 40.2588 & 20.9917 & 0.005464 \\
\hline 200 & 38.7111 & 10.2686 & 0.326030 & 28.2076 & 10.6241 & 0.016768 \\
\hline 300 & 28.7575 & 7.0134 & 0.4343792 & 24.8603 & 7.1662 & 0.005954 \\
\hline 400 & 24.7538 & 5.4937 & 0.567867 & 23.2607 & 5.4352 & 0.007028 \\
\hline 500 & 23.6020 & 4.5598 & 0.686287 & 22.0538 & 4.3906 & 0.007523 \\
\hline 600 & 25.9908 & 4.5204 & 0.844283 & 21.6818 & 3.7011 & 0.013187 \\
\hline 700 & 22.5403 & 4.0063 & 0.957321 & 20.9849 & 3.2029 & 0.009379 \\
\hline 800 & 23.5703 & 3.7902 & 1.083072 & 20.9142 & 2.8390 & 0.012689 \\
\hline 900 & 20.8165 & 3.0932 & 1.214740 & 20.4186 & 2.5502 & 0.019404 \\
\hline 1000 & 21.7473 & 3.1263 & 1.425595 & 20.1255 & 2.3144 & 0.012848 \\
\hline 2000 & 20.9057 & 2.2248 & 2.684881 & 19.2184 & 1.2645 & 0.020227 \\
\hline 3000 & 19.8222 & 1.7355 & 3.965261 & 18.8203 & 0.9091 & 0.028058 \\
\hline 4000 & 20.1457 & 1.5452 & 5.352318 & 18.6524 & 0.7287 & 0.051087 \\
\hline 5000 & 20.7908 & 1.3852 & 6.735791 & 18.5443 & 0.6174 & 0.069790 \\
\hline 6000 & 21.2699 & 1.2893 & 7.905440 & 18.4808 & 0.5424 & 0.44211 \\
\hline 7000 & 19.5028 & 1.1256 & 9.373311 & 18.4179 & 0.4870 & 0.070322 \\
\hline 8000 & 19.3336 & 1.0575 & 10.55971 & 18.3841 & 0.4448 & 0.085900 \\
\hline 9000 & 20.0250 & 1.0170 & 12.016419 & 18.3386 & 0.4112 & 0.073828 \\
\hline 10.000 & 18.9144 & 0.9316 & 13.356938 & 18.3299 & 0.3842 & 0.099772 \\
\hline 100.000 & 18.5929 & 0.2923 & 132.858870 & 18.1452 & 0.1044 & 9.898161 \\
\hline 150.000 & 18.1994 & 0.2360 & 197.491174 & 18.1362 & 0.0847 & 18.271538 \\
\hline 300.000 & 18.1876 & 0.1668 & 397.804523 & 18.1265 & 0.0595 & 136.145204 \\
\hline
\end{tabular}

Sumber: Data Diolah (2017).

Berdasarkan Tabel 2 dapat dilihat bahwa:

1. Nilai kontrak Opsi Tipe Binary menggunakan metode Monte Carlo sebesar 18.1876 dengan standar error 0.1668 . Sedangkan nilai kontrak Opsi Tipe Binary menggunakan metode Quasi Monte Carlo barisan bilangan acak Faure diperoleh nilai sebesar 18.1265 dengan standar error 0.0595. Tabel 2 menunjukkan metode Quasi Monte Carlo waktu eksekusi yang dihasikan lebih cepat dibandingkan dengan metode Monte Carlo.

2. Metode Monte Carlo pada simulasi ke- 10.000 nilai opsi menunjukkan konvergen pada 18.9144 dengan standard error 0.9316 dan waktu eksekusi sebesar 13.356938 detik. Metode Quasi Monte Carlo barisan bilangan Faure nilai opsi lebih cepat menunjukkan kekonvergenan. Simulasi ke-3000 nilai opsi konvergen pada 18.8203 dengan standard error-nya yaitu 0.901 dan waktu eksekusi 0.028058 detik.

Dengan demikian dapat diketahui bahwa metode Quasi Monte Carlo barisan bilangan acak Faure nilai opsi yang dihasilkan lebih cepat menuju konvergen dibandingkan dengan metode Monte Carlo. Hal ini menunjukkan bahwa pada saat simulasi pemilihan bilangan acak Quasi Monte Carlo dilakukan berdasarkan nilai dimensi dan basis. Sedangkan pada metode Monte Carlo saat mensimulasi menggunakan Crude Monte Carlo atau bilangan acak kasar. 


\section{SIMPULAN DAN SARAN}

Berdasarkan hasil pembahasan yang telah diuraikan, diperoleh kesimpulan bahwa menentukan nilai kontrak opsi tipe binary pada komoditas kakao mengunakan metode Quasi Monte Carlo barisan bilangan acak Faure dapat dilakukan berdasarkan nilai $\left(S_{0}\right),(K),(T),(r)$, $(\sigma)$, dan $(N)$. Selanjutnya mensimulasi nilai komoditas kakao mengunakan Quasi Monte Carlo Barisan Bilangan acak Faure. Setelah mendapatkan nilai simulasi, kemudian menghitung nilai pay-off asset-or-nothing. Langkah selanjutnya

yaitu menaksir nilai opsi dengan merata-ratakan nilai pay-off dari opsi put tersebut.

Berdasarkan kedua hasil tersebut nilai kontrak opsi tipe binary yang dihitung dengan metode Quasi Monte Carlo standard error lebih cepat mendekati nol dan nilai opsi lebih cepat menuju konvergen dibandingkan dengan metode Monte Carlo.

Adapun hal-hal yang disarankan peneliti untuk dapat dijadikan pertimbangan dalam penelitian selanjutnya yaitu simulasi dengan metode Quasi Monte Carlo barisan bilangan acak lain yaitu Van der corput dan Sobol untuk menentukan nilai opsi. Kontrak opsi tipe binary dapat diterapkan pada bidang asuransi dalam penentuan nilai premi.

\section{DAFTAR PUSTAKA}

Badan Perijinan \& Penanaman Modal Daerah Provinsi Kalimantan Timur, 2009. Prospek Menggiurkan Investasi Budidaya Kakao. Samarinda.

Bodie, Kane \& Marcus, 2006. Investasi. 6th ed. Jakarta: Salemba Empat.

Boyle, P.P., 1977. Option A Monte Carlo Approach. Journal of Financial Economics 4:323-338.

Elfiana, 2014. Kebijakan Pajak EksporTerhadap Perkembangan Ekspor Kakao di Indonesia. Lentera, 14. No. 10, pp.25-32.

Hull, J.C., 2009. Options, Futures, and Other Derivatives. New Jersey: Pearson Prentice Hall.

Joy, C., Boyle, P. \& Ken Seng Tan, 1996. Quasi Monte Carlo in Numerical Finance. Management Science, 42(6), pp.926-38.

Kroese, D.P., Taimre, T. \& Botev, Z.I., 2011. Handbook of Monte Carlo Methods. New Jersey: John Wiley \& Sons.

Mahayoga, I.G.P.N., Dharmawan, K. \& Ida Harini, L.P., 2014. Penentuan Harga Kontrak Opsi Tipe Eropa Menggunakan Metode Quasi Monte Carlo dengan Barisan Kuasi-Acak Halton. E-Jurnal Matematika, 3(4), pp.154 -159.

Paskov, S.T., 1995. Faster Valuation of Financial Derivatives. Journal of Portofolio Management, 22:113-120.

Siahaan , H., 2008. Seluk Beluk Perdagangan Instrumen Derivatif. Jakarta: PT.Elex Media Komputindo.

Uyanto, S.S., 2007. Perbandingan Metode Quasi Monte Carlo dengan Barisan Kuasi-Acak Halton dan Barisan Kuasi-Acak Sobol dalam Option Pricing. Majalah Ekonomi dan Komputer No 1 Tahun XV, pp.27-37. 